Goldschmidt 2021 Abstract

https://doi.org/10.7185/gold2021.3835

\section{Thermodynamic study on zeolite formation at cement/clay interfaces}

\author{
BIN MA ${ }^{1}$ AND BARBARA LOTHENBACH ${ }^{2}$
}

${ }^{1}$ Swiss Federal Laboratories for Materials Science and Technology (Empa)

${ }^{2}$ Empa

Presenting Author: bin.ma@empa.ch

Thermodynamic study on zeolite formation at cement/clay interfaces

Bin MA, Barbara LOTHENBACH

Empa, Überlandstrasse 129, 8600 Dübendorf, Switzerland.

Email address: bin.ma@empa.ch, barbara.lothenbach@empa.ch

Zeolites can form in the long-term interaction zone between cements and clays, in alkali-activated cements, at the surface of cements exposed to seawater and to carbonation. Due to their high structural variability in terms of $\mathrm{Al} / \mathrm{Si}$ and extra-framework cations, zeolite stability is poorly known, which leaves a serious gap in thermodynamic data and thus disables reliable predictions for the interaction of cement with the surrounding environment (e.g., adjacent clays and rock forming minerals) [1-2]. This draws forth the objective to determine the thermodynamic data of pure zeolites experimentally and systematically.

In this study, natural and commercially available zeolites were collected and hydrothermal methods were used to synthesize zeolites. Characterization by XRD, TGA, SEM-EDS, and FT-IR showed that the obtained zeolites were highly pure and had different cations $\left(\mathrm{Na}^{+}, \mathrm{K}^{+}\right.$, and $\left.\mathrm{Ca}^{2+}\right)$, diverse secondary building units (S4R, S6R, D4R, D6R, 4=1, 5-1, and 4-4=1), and various frameworks (ANA, GIS, PHI, LTA, SOD, CAN, MER, CHA, FAU, NAT, MOR, STI, and HEU). Zeolite dissolution experiments were carried out at different temperatures to obtain experimental solubility products $\left(\mathrm{K}_{\mathrm{sp}}\right)$. Based on the $\log \mathrm{K}_{\mathrm{sp}}$ and the variations with temperature, the standard Gibbs free energy, enthalpy, and entropy were computed using GEM-Selektor, where available experimental entropy and heat capacity were used. Predominance diagrams of zeolite-clay/mica$\mathrm{SiO}_{2} / \mathrm{Al}(\mathrm{OH})_{3}$-cement minerals in the relevant chemical subsystems were successfully established using PHREEQCPhreePlot (Fig. 1), indicating that only a limited number of zeolites are expected to form at the cement/clay or rock interface. A good consistency of the thermodynamic data was verified and the kind of zeolite stabilized depends strongly on the dominant cation.

The experimentally determined thermodynamic data for zeolites allow predicting under which conditions zeolites might form and are expected to close an important gap in long-term thermodynamic predictions needed in the context of radioactive waste disposal.

References

[1] Lothenbach B. et al., Phys. Chem. Earth. Parts A/B/C, 99, 77-94 (2017).

[2] Blanc, P. et al., Appl. Geochem. 55, 95-107 (2015).

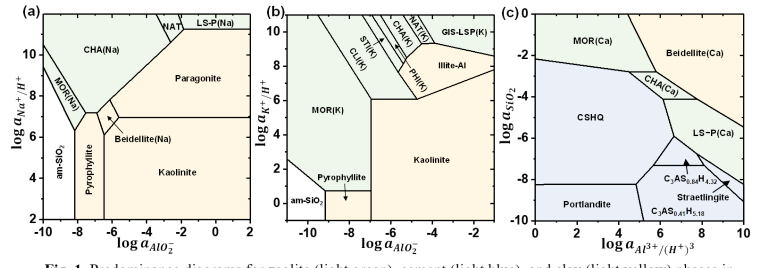

Fig. 1. Predominance diagrams for zeolite (light green), cement (light blue), and clay (light yellow) phases in respectively, saturated with amorphous $\mathrm{SiO}_{2}\left(\right.$ am- $\left.-\mathrm{SiO}_{2}\right)$, am-SiO $\mathrm{Si}_{2}$, and portlandite at $25^{\circ} \mathrm{C}$
ra $\mathrm{C}$ 